\title{
Development of antenatal psychosocial stress scale for pregnant women in Kerala, India
}

\author{
R. Devisree ${ }^{1 *}$, C. Nirmala ${ }^{1}$, P. S. Indu ${ }^{2}$, S. Remadevi ${ }^{3}$
}

\begin{abstract}
${ }^{1}$ Department of Obstetrics and Gynecology, Sree Avittom Thirunal Hospital, Medical College, Thiruvananthapuram, Kerala, India

${ }^{2}$ Department of Community Medicine, ${ }^{3}$ Department of Clinical Epidemiology Research and Training Centre, Medical College, Thiruvananthapuram, Kerala, India
\end{abstract}

Received: 17 January 2018

Accepted: 28 February 2018

\section{*Correspondence:}

Dr. R. Devisree,

E-mail: drdevisreekishore@gmail.com

Copyright: (C) the author(s), publisher and licensee Medip Academy. This is an open-access article distributed under the terms of the Creative Commons Attribution Non-Commercial License, which permits unrestricted non-commercial use, distribution, and reproduction in any medium, provided the original work is properly cited.

\begin{abstract}
Background: Psychosocial stress in pregnancy, defined as, "the imbalance that a pregnant woman feels when she cannot cope with demands is expressed both behaviourally and physiologically". The purpose of this study was to develop a culturally appropriate and locally relevant scale for measuring antenatal psychosocial stress.

Methods: Cross sectional design was used for the study. Participants were antenatal women attending outpatient department of both government and private sector. Twenty-nine item questionnaires to identify psychosocial stress among antenatal women was developed by conducting focus group discussions and in-depth interviews among socioeconomically diverse population and different parity and among uncomplicated and complicated pregnancies. By administering the questionnaire among 190 participants, Reliability and Validity were estimated. Factor analysis was done for item reduction. Poor loading, wrong loading and cross loading items were removed from the questionnaire. Convergent validity assessed with prenatal psychosocial stress scale among 55 antenatal women.

Results: The final questionnaire has 10 items. Item-total correlation was found to be greater than 0.2 for all the items. The internal consistency coefficient (Cronbach's alpha) for the 29-item questionnaire was 0.878 . Test-retest reliability was 0.98 (95\% CI 0.96-0.99). Further, factor analysis was done to demonstrate construct validity. The interrater reliability was 0.98 (95\% CI- 0.96-0.99).

Conclusions: Based on analysis of psychometric properties, the conclusion is that the 10 items questionnaire is a reliable, simple, valid and easy to administer tool for use among antenatal women of all settings.
\end{abstract}

Keywords: Item analysis, Pregnancy, Psychosocial stress, Reliability, Validity

\section{INTRODUCTION}

The American College of Obstetricians and Gynecologists released a 2006 committee opinion stating that psychosocial stress may predict a woman's attentiveness to personal health matters, her use of prenatal services, and the health status of her offspring. In this committee opinion, ACOG advocated screening all women for psychosocial stress and other psychosocial issues during each trimester of pregnancy and the postpartum period. ${ }^{1}$

In the few studies conducted to date, associations have been noted between antenatal psychosocial stress and poor weight gain and other adverse maternal outcomes. Many of these studies were limited, however, in their sample size, select populations, or assessment of potential covariates (e.g. use of non-validated measures or medical 
records only). Some of these identified factors are known to be associated with adverse birth outcomes like preterm delivery, low birth weight, intra uterine growth restriction, preterm premature rupture of membranes, preeclampsia etc, so determining their associations with psychosocial stress is paramount. $^{2}$ Also, associations have been noted between antenatal psychosocial stress and domestic violence, depressive symptoms, psychiatric diagnoses, chronic medical disorder etc. ${ }^{3}$

Kerala is a state with $100 \%$ literacy and nearly $100 \%$ institutional delivery and access to health care. Still the maternal mortality rate and morbidity, neonatal mortality rate and morbidity contributed by preterm labour and low birth rate are on higher side. In a state like Kerala where social and other family factors are undergoing a change, pregnancy has become a matter of stress for many families. Hence the importance of development of a psychosocial stress scale so that our antenatal protocol can be modified by incorporating simple questions to assess the stress so that adequate interventions can be implemented.

\section{METHODS}

The aim of this study was to develop a culturally appropriate and locally relevant scale for measuring psychosocial stress among antenatal women. Cross sectional design was used for the study. The study was conducted from December 2010 to December 2011 at a Tertiary Care Government teaching hospital, Maternal and Child hospital in private sector and at a Maternal and Child hospital in secondary care sector.

Sample size was 190. Author enrolled the antenatal women in age group of 18 to 40 years attending outpatient department of Sree Avittom Thirunal hospital (Tertiary care Government teaching hospital), Maternal and Child hospital in private sector and Women and Child Hospital (Maternal and Child hospital in secondary care sector). Those who have known psychiatric illnesses were excluded from the study.

\section{Steps in scale development}

\section{Item generation}

For development of initial construct textbooks and published literature about stress measurements were reviewed. A qualitative method consisting of focus group discussions and in-depth interviews were carried out. A focus group discussion guide was prepared. Informed consent of the interviewees was taken. The purpose of the focus group discussion was to tap opinions and attitudes of pregnant woman regarding the factors leading to psychosocial stress in pregnancy. Two focus group discussions were conducted. Tape recording of the focus group discussions was done. The focus group discussion was conducted by three experts in Obstetrics and Gynaecology, Community Medicine and Sociology and the investigator. In depth interviews were conducted among a socioeconomically diverse population of different parity and diverse population of antenatal woman unemployed, employed, belonging to both high and low socioeconomic status, and also among uncomplicated and complicated pregnancies. The data obtained from in depth interviews and focus group discussions were transcribed, translated and analyzed. Content analysis was done, and domains identified. Under each domain items were listed.

\section{Identification of items}

Identification of items were done after deleting repetitions and overlapping items.

\section{Item selection}

The items which were getting maximum response were selected. Rank ordering of the initial items were done by experts.

\section{Item wording and sequencing}

The wording was simple, comprehensible to the target population and unambiguous. The items had a logical flow and it didn't jump from one area to another.

\section{Response formatting and selection of type of scale}

The items were set in a question format and the response was set in a three-point scale namely Thurstone's method of anchoring was used which included 0 which indicates never or not applicable.1indicates often, 2 indicates always

\section{Pre-tests}

Selected items were pretested among a sample of respondent population (twenty antenatal women) and among five Colleagues (post graduates) in obstetrics and gynecology to ensure face and content validity.

\section{Pilot study}

A pilot study was done among participants (twenty antenatal women) to know the comprehensibility, wording and structure of items and also the feasibility of administration

\section{Assessment of psychometric properties}

- Reliability assessment: Done using test retest reliability, inter rater reliability and internal consistency (Cronbach alpha values).

- Validity assessment: KMO (Kaiser Meyer Olkin) and Bartlett's test was carried out to ensure whether data is factorizable and sample is adequate. Face and content validity was assessed by experts. Construct validity was demonstrated through factor analysis. 
Principal component factor analysis was done for the initial extraction of factors and varimax rotation to bring about a simplification of the initial solution. Convergent validity assessed with Pre-natal psychosocial stress scale among fifty-five antenatal women.

\section{RESULTS}

From focus group discussions and in-depth interviews, four domains were identified after content analysis. The items were framed under the following subheadings which included spousal related mainly attributes or behaviour, family related, pregnancy related, personal matters, related to house hold activities, related to job and related to sexual life. Rank ordering done, and items were reduced to a total of twenty-nine.

Mean and standard deviation of each items calculated. Item total correlation indicates the correlation of that item with total scale. The item total correlations for each item ranged between 0.2 to 0.6 (Table 1 ).

Table 1: Item-total correlation of 29 items $(n=190)$.

\begin{tabular}{|c|c|c|}
\hline Items & $\begin{array}{l}\text { Item-total } \\
\text { correlation }\end{array}$ & $\begin{array}{l}\text { Alpha if } \\
\text { item deleted }\end{array}$ \\
\hline Concern regarding the investigations done during pregnancy & 0.32 & 0.88 \\
\hline Concern about illness during pregnancy & 0.40 & 0.88 \\
\hline Concern about expenses during pregnancy & 0.68 & 0.83 \\
\hline Concern about delivery complications & 0.47 & 0.88 \\
\hline Concern regarding labour pains & 0.29 & 0.88 \\
\hline Concern regarding the behaviour of doctors and sisters in the labour room & 0.44 & 0.88 \\
\hline Concern regarding communication with doctors regarding your illness in pregnancy & 0.56 & 0.87 \\
\hline Concern regarding gender of your baby & 0.47 & 0.87 \\
\hline Concern regarding fear of caesarean section & 0.40 & 0.88 \\
\hline Concern regarding health of your baby & 0.22 & 0.88 \\
\hline $\begin{array}{l}\text { Are you worried as you do not get adequate rest periods in between domestic work / in job } \\
\text { place }\end{array}$ & 0.20 & 0.88 \\
\hline Concern about not getting help from anybody else for domestic activities/in work place & 0.19 & 0.88 \\
\hline Are you worried about unemployment? & 0.16 & 0.88 \\
\hline Concern about looking after elder children while pregnant & 0.34 & 0.88 \\
\hline Concern about not having freedom to make decisions & 0.48 & 0.87 \\
\hline Concern about children's/husband's/anyone's illness in the family & 0.17 & 0.88 \\
\hline Concern about missing own parents while pregnant & 0.34 & 0.88 \\
\hline Concern about lack of physical/ financial / emotional support from your family & 0.56 & 0.87 \\
\hline Concern about verbal abuse by husband's in laws & 0.69 & 0.87 \\
\hline Concern about staying among in laws & 0.64 & 0.87 \\
\hline Concern about husband not with the wife while pregnant & 0.38 & 0.88 \\
\hline Concern about husband's unemployment & 0.31 & 0.88 \\
\hline Concern about husband's inattention & 0.49 & 0.87 \\
\hline Concern about husband's bad friends & 0.59 & 0.87 \\
\hline Concern about husband's alcoholism & 0.47 & 0.87 \\
\hline Concern about husband's smoking & 0.51 & 0.87 \\
\hline Concern about husband's violence & 0.64 & 0.87 \\
\hline Are you tensed about changes in sexual pattern while pregnant & 0.10 & 0.88 \\
\hline
\end{tabular}

The item total correlations for each item ranged between 0.2 to 0.6 . If the correlation is $>0.2$, the items can be included. Internal consistency reliability assessed using Cronbach alpha (0.8784) of 29 items.

\section{Factor analysis for factor reduction}

The initial KMO was 0.823 and Bartlett's test of sphericity was significant, which ensured that the data was factorizable (as KMO was >0.6) (Table 2).
Table 2: KMO and Bartlett's test.

\begin{tabular}{|c|c|c|}
\hline \multicolumn{2}{|c|}{$\begin{array}{l}\text { Kaiser-Meyer-Olkin measure of } \\
\text { sampling adequacy }\end{array}$} & 0.823 \\
\hline \multirow[t]{3}{*}{$\begin{array}{l}\text { Bartlett 's test of } \\
\text { sphericity }\end{array}$} & Approx. Chi-Square & 2434.212 \\
\hline & $\mathrm{d}_{\mathrm{f}}$ & 406 \\
\hline & Sig & 0.000 \\
\hline
\end{tabular}

$\mathrm{KMO}>0.6$ 
Principal component analysis yielded 4 components, with Eigen value more than 1 as evidenced by scree plot (Figure 1).

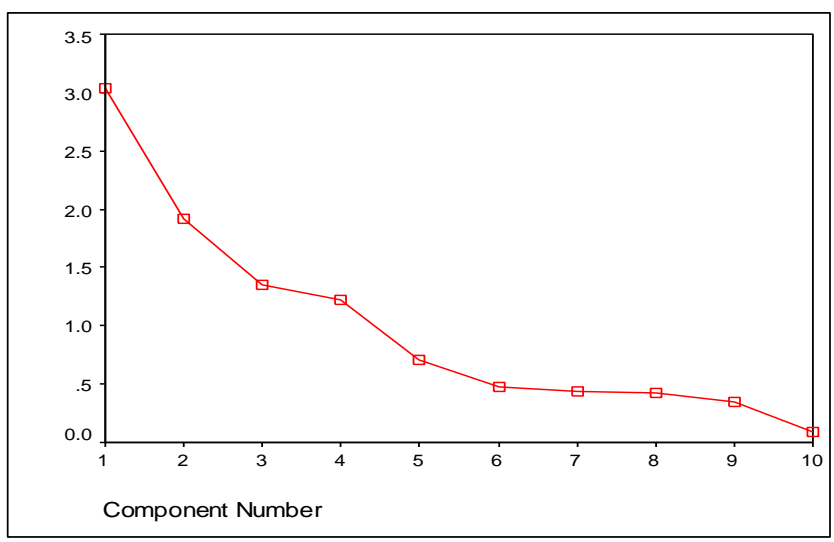

Figure 1: Scree plot.
Rotated component matrix of the 10 items questionnaire after factor analysis and item reduction (Table 3 ).

In the factor analysis, author got four components that showed $75.2 \%$ of variance (Table 4$)$. In $1^{\text {st }}$ component that is pregnancy related there are 3 items. It explained $30 \%$ of variance. In $2^{\text {nd }}$ component that is hospital or provider related there are 3 items. It explained $19.1 \%$ of variance. In $3^{\text {rd }}$ component that is work related there are 2 items. It explained $13.4 \%$ of variance. In $4^{\text {th }}$ component that is spousal related there are 2 items. It explained $12.1 \%$ of variance.

The communalities of all variables are above 0.6. Thus, after factor analysis and item reduction, we got four components which contained a total of 10 items. Nineteen items were deleted from the original questionnaire. Final list of items in the questionnaire (Table 5).

Table 3: Rotated component matrix of the 10 items questionnaire.

\begin{tabular}{|lll|}
\hline Components & Items & Factor loadings \\
\hline $\begin{array}{l}\text { (Pregnancy } \\
\text { related) }\end{array}$ & Concern regarding the investigations done during pregnancy & 0.807 \\
\hline \multirow{3}{*}{$\begin{array}{l}\text { (Hospital /provider } \\
\text { related) }\end{array}$} & $\begin{array}{l}\text { Concern about illness during pregnancy } \\
\text { Concern about delivery complications }\end{array}$ & 0.823 \\
\hline & $\begin{array}{l}\text { Concern regarding labour pains } \\
\text { Concern regarding the behaviour of doctors and sisters in labour room } \\
\text { pregnancy. }\end{array}$ & 0.708 \\
\hline (Work related) & $\begin{array}{l}\text { Are you worried as you do not get adequate rest periods in between } \\
\text { domestic work / in job place }\end{array}$ & 0.867 \\
\cline { 2 - 3 } & $\begin{array}{l}\text { Concern about not getting help from anybody else for domestic } \\
\text { activities/in work place. }\end{array}$ & 0.740 \\
\hline (Spousal related) & Concern about husband's alcoholism & 0.973 \\
\hline
\end{tabular}

Table 4: Total variance.

\begin{tabular}{|c|c|c|c|c|c|c|}
\hline & \multicolumn{3}{|c|}{ Extraction sums of squared loadings } & \multicolumn{3}{|c|}{ Rotation sums of squared loadings } \\
\hline Component & Total & $\begin{array}{l}\text { Percentage } \\
\text { variance }\end{array}$ & $\begin{array}{l}\text { Cumulative } \\
\text { percentage }\end{array}$ & Total & $\begin{array}{l}\text { Percentage } \\
\text { variance }\end{array}$ & $\begin{array}{l}\text { Cumulative } \\
\text { percentage }\end{array}$ \\
\hline 1 & 3.042 & 30.416 & 30.416 & 1.974 & 19.735 & 19.735 \\
\hline 2 & 1.918 & 19.184 & 49.600 & 1.964 & 19.640 & 39.375 \\
\hline 3 & 1.349 & 13.494 & 63.093 & 1.925 & 19.247 & 58.622 \\
\hline 4 & 1.218 & 12.183 & 75.277 & 1.665 & 16.655 & 75.277 \\
\hline
\end{tabular}

Test retest reliability was tested in a sample of 30 pregnant women. The scale was administered twice with an interval of 2 week by the investigator to the same pregnant women. Intra class correlation coefficient was 0.9845 (95\% CI 0.96-0.99).

Inter-rater reliability was examined in a sample of 30 pregnant women. Investigator and a college administered the scale separately during the same visit. Intra class correlation coefficient was 0.9853 (95\% CI 0.96-0.99). Internal consistency reliability of 10 items was measured using Cronbach alpha of 10 items and it was 0.733 which is an acceptable value.

Convergent validity was assessed among 55 antenatal women. The intra class correlation coefficient was 0.854 (95\% CI -0.692-0.93). The item total correlations for each item ranged (0.2-0.6). 
Table 5: Final 10 items and item total correlation of 10 items.

\begin{tabular}{|lll|}
\hline Items & $\begin{array}{l}\text { Item-total } \\
\text { correlation }\end{array}$ & $\begin{array}{l}\text { Alpha if } \\
\text { item deleted }\end{array}$ \\
\hline Q1 Concern regarding the investigations done during pregnancy & 0.36 & 0.70 \\
\hline Q2 Concern about illness during pregnancy & 0.47 & 0.68 \\
\hline Q4 Concern about delivery complications & 0.52 & 0.68 \\
\hline Q5 Concern regarding labour pains & 0.30 & 0.71 \\
\hline Q6 Concern regarding the behaviour of doctors and sisters in labour room & 0.40 & 0.69 \\
\hline Q7 Concern regarding communication with doctors regarding your illness in pregnancy & 0.47 & 0.68 \\
\hline $\begin{array}{l}\text { Q11 Are you worried as you do not get adequate rest periods in between domestic } \\
\text { work/in job place. }\end{array}$ & 0.29 & 0.71 \\
\hline $\begin{array}{l}\text { Q12 Concern about not getting help from anybody else for domestic activities/ in work } \\
\text { place }\end{array}$ & 0.28 & 0.71 \\
\hline Q26 Concern about husband's alcoholism. & 0.31 & 0.71 \\
\hline Q28 Concern about husband's violence & 0.45 & 0.68 \\
\hline
\end{tabular}

Principal component analysis yielded 4 components, with Eigen value more than 1.

\section{DISCUSSION}

Psychosocial stress factors are known to be associated with adverse birth outcomes like Preterm delivery, low birth weight, stillbirth, pre-eclampsia etc. Hence it is important that stress of our antenatal women needs to be assessed. Hence a scale to measure the stress among antenatal women has to be developed as there are no such scales developed in Kerala or in India. Available scales are developed in western countries which are not culturally and locally acceptable and applicable in the set up. Hence the aim of my study is to develop a culturally appropriate scale for measuring psychosocial stress among antenatal women. Qualitative methods including focus group discussions and in-depth interviews were done for item generation and free listed. Content analysis done, and domains evolved. Under each domain items evolved. The selected items were pretested and piloted and administered to a sample of 190 antenatal women. The results obtained were discussed as follows.

The final 10 item Psychosocial stress assessment scale for antenatal women had internal consistency reliability (Cronbach alpha) of 0.733 which is equal to the acceptable level of 0.7 . The test-retest reliability was 0.98 , when re administered within a period of 2 weeks. The inter rater reliability was 0.98 , when administered by 2 separate persons. The item total correlation for each item ranged (0.2-0.5). In a study on development of a stress scale for pregnant women in South Asian context: A-Z stress scale by Kazi et al, the scale had 30 items with Cronbach alpha of 0.82 , test retest reliability of 0.86 and inter rater reliability of $0.91 .^{4}$ The item total correlation for each item ranged between (0.2-0.5). In another study by Harville EW et al. In life events, perceived stress, state anxiety, trait anxiety, and pregnancy related anxiety were all positively correlated with one another with correlation coefficients in the range $(0.2-0.5) .^{5}$ In present study population, $75.3 \%$ of participants had stress of which $23.2 \%$ of participants had severe stress and $52.1 \%$ of participants had moderate stress. Only $24.7 \%$ of participants reported no stress. In a study in Psychosocial stress during pregnancy by Woods SM et al. ${ }^{3}$ Six percentage of women reported high stress, $78 \%$ reported low or moderate stress, and $16 \%$ reported no stress.

The questions developed for the scale conceived to represent the four domains of 1 - pregnancy related, 2 hospital related, or provider related, 3 - work related,4spousal related. All the factors derived by factor analysis could be labelled by the researcher. In present study population, of all the stressors the most significant stressor is that related to pregnancy, out of which major component were anxiety related to hospital care. Other factors related to pregnancy were anxiety developed about the complications of this pregnancy and also during delivery. For primigravidas, fear of labour pain is an important stressor. In this study population, $48.4 \%$ of participants responded that most of the time they were concerned about investigations done during pregnancy. $54.2 \%$ of the participants responded that they were concerned about their illness during pregnancy most of the time. $50.5 \%$ of participants responded that most of the time they were concerned about delivery complications.

In present study population, $41.1 \%$ of the participants reported that most of the time they were concerned about labour pains. $16.8 \%$ of the participants responded that most of the time they were concerned about the behaviour of doctors and sisters in the labour room.

Only $7.9 \%$ of the participants responded that they were concerned about inadequate communication with doctors regarding their illness in pregnancy.

In a study in psychosocial stress during pregnancy by Woods SM et al having two or more medical problems increased the odds of high psychosocial stress during 
pregnancy by 3 to 4 folds. ${ }^{3}$ Stress situations, overwork, bad social conditions, bad obstetric history, pregnancy complications and unsatisfactory care are responsible for fear during pregnancy. ${ }^{6}$

A descriptive correlational study conducted by Gupton identified that, women with complicated pregnancies perceive their overall risk and risk for special pregnancy outcome as significantly higher than women with

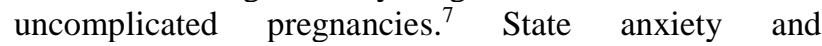
biomedical risk were positively related to perception of risk. According to Hoffman, antenatal testing brings it with emotional stress as well as the ability to diagnose abnormalities. ${ }^{8}$

A study conducted by Kang identified that fear related to pain was most frequent fear of women and socioeconomic problems take important role in fear and anxiety of pregnant women. ${ }^{9}$ Primigravidae noted more fear and anxiety about pregnancy compared to multigravidae and more intensity was noted during early half of gestational period. An experimental study by Kmitha among 116 pregnant women identified that the level of anxiety is significantly higher in hospitalized women with high risk pregnancy when compared to women with low risk pregnancy. ${ }^{10}$

Thirty percentage of the participants responded that most of the time they were concerned about inadequate rest periods in between domestic work/job place. $30.5 \%$ of the participants responded that most of the time they were concerned about inadequate help from others in domestic activities or in work place.

A study done by Rickert identified that there is a strong relationship between working for more than 15 hours and small for gestational age delivery. ${ }^{11}$

Job related psychological stress may be as much of a burden to employed pregnant women similar to physical exertion. The pressure of a job with low rewards, high demands, low decision making power or other causes of worry and pressure may also place fetus at risk (Landisbergis 1996). ${ }^{12}$

A cross sectional study done by Chandola identified that work to family conflict and family to work conflict could arise from inability to combine multiple roles and result in stress and ill health. ${ }^{13}$

Strenuous working conditions and occupational fatigue in pregnancy have been associated with preterm delivery and low birth weight among working women (Homer 1990). ${ }^{14}$

A cohort study done by Anderson identified that fixed night work during pregnancy increases the risk of late fetal loss. ${ }^{15}$
In this study population, $37.4 \%$ of the participants responded that most of the time they were concerned about husband's alcoholism. $23.7 \%$ of the participants responded that most of the time they were concerned about husband's violence.

Husband's alcoholism, domestic violence, unemployment, inattention, bad friends etc produce much stress on antenatal women. In a study in psychosocial stress during pregnancy by Woods SM et al domestic violence increased the odds of high psychosocial stress during pregnancy by 3 to 4 folds. ${ }^{3}$ A study conducted by Wilson identified that most common stressful life events during pregnancy are residential moves, increased arguing with husband or partner and family members, hospitalization, financial hardship and death of loved ones. ${ }^{16}$

According to a study done by Goldstein it was identified that intimate partner's physical assault is predictive of pregnant women's psychosocial vulnerability and they showed loss of control in their relationship. ${ }^{17}$

In the traditional society, the older women at home provided the needed help, guidance and support to the pregnant woman regarding their care. In the present century, as the trend moves towards the nuclear family, support system is gradually dwindling. Woman resort to hospital delivery and depend more on the health care personnel for service, support and guidance.

In present study most of the findings are consistent with various studies done in developed world. This may be due to education, employment and other levels of Kerala women in par with developed world.

The strength of the study was that the study was done in 3 settings tertiary centres, secondary centre and in a private hospital thereby ensuring generalisability. Desired level of reliability had been reached. The final internal consistency reliability (Cronbach alpha) was 0.7333 . Test-retest reliability for the scale items was respectably high suggesting that the scale is reliable over time. The inter rater reliability of stressors was high suggesting that if the scale was administered by different interviewers its understandability would remain the same. The final 10 item questionnaire explained $75 \%$ variance.

The limitations of the study were that only antenatal women of Trivandrum district were studied. Due to time constraints and resource constraints, criterion validity and receiver operator characteristic curve to identify the cut off could not be assessed.

Decreasing high antenatal psychosocial stress in itself will improve maternal and fetal wellbeing. Decreasing high stress and/or addressing associated risk factors may also decrease the risk of adverse pregnancy outcomes. With identification of these other factors, health care 
providers are provided with additional specific foci for intervention.

Author recommend further predictive studies to validate this scale by examining associations of stress with pregnancy outcome such as premature labour and low birth weight and the psychological well-being of women such as anxiety and depression. Also, author recommend validation of this scale in another setting mainly in the peripheral centres as well as in other parts of the state.

\section{CONCLUSION}

Based on the analysis of psychometric properties, it can be concluded that the 10 items questionnaire is a reliable, simple valid and easy to administer tool for use among antenatal women of all settings from primary care centres to tertiary care centres and private institutions. This tool can be used to assess psychosocial stress among pregnant women which can be asked as a part of history taking during antenatal care.

\section{ACKNOWLEDGMENTS}

Authors would like to thank medical superintendent of Sree Avittom Thirunal Hospital, all the colleagues, and the antenatal women for their incredible support and encouragement. Author also thank the Head of Department of Maternal and Child Hospital in the private sector and the medical superintendent of Women and Child hospital in the secondary care sector for their valuable suggestions and guidance.

Funding: No funding sources

Conflict of interest: None declared

Ethical approval: The study was approved by the Institutional Ethics Committee

\section{REFERENCES}

1. ACOG committee psychosocial risk factors perinatal screening and Intervention. Obstet Gynecol. 2006;108:469-77.

2. Neggers Y, Goldenberg R, Cliver S, Hauth J. The relationship between psychosocial profile, health practices, and pregnancy outcomes. Acta obstetricia et gynecologica Scandinavica. 2006;85(3):277-85.

3. Woods SM, Melville JL, Guo Y, Fan MY, Gavin A. Psychosocial stress during pregnancy. Am J Obstet Gynecol. 2010 Jan 1;202(1):61-e1.

4. Kazi Z, Fatmi J, Hatcher U. Niaz-Development of a stress scale for pregnant women in the South Asian context: the A-Z Stress scale. Available at: http://apps.who.int/iris/bitstream/10665/117646/1/15_2 _2009_0353_0361.pdf.

5. Harville EW, Savitz DA, Dole N, Herring AH, Thorp JM. Stress questionnaires and stress biomarkers during pregnancy. J Women's Health. 2009;18(9):1425-33.

6. Zdziennicki A. Fear as a risk factor in perinatology. Wiadomosci lekarskie (Warsaw, Poland: 1960). 1994 Sep;47(17-18):698-9.

7. Gupton A, Heaman M, Cheung LW. Complicated and uncomplicated pregnancies: women's perception of risk. J Obstet Gynecol Neonatal Nursing. 2001;30(2):192-201.

8. Hoffman NS. Stress factors related to antenatal testing during pregnancy. J Perinatol. 1990;10(2):195-7.

9. Kang JH. A study on fear and anxiety of pregnancy women . Journal of Korean Academic Nursing. 1980;10(2):1-12.

10. Kmita G, Barańska M, Ciastoń-Przecławska E, Cerańska-Goszczyńska H, Urmańska W. Psychological aspects of high risk pregnancy in hospitalized women-toward the change of the existing model of care. Ginekologia polska. 1998;69(12):1025-31.

11. Rickert VI, Wiemann CM, Goodrum LA, Berenson AB. Employment and health-risk behaviors among pregnant adolescents. J Pediat Adol Gynecol. 1998;11(2):79-84.

12. Landisbergis. Women work and well-being. J Health Social Behavior. 1996;33(8):200-4.

13. Chandola T, Martikainen P, Bartley M, Lahelma E, Marmot M, Micikazu S, et al. Does conflict between home and work explain the effect of multiple roles on mental health. J Epidemiol. 2000;10(1):68-74.

14. Homer CJ. Work related psychosocial stress and risk of preterm baby. Am J Public Health. 1990;80(2): 173-7.

15. Zhu JL, Hjollund NH, Andersen AM, Olsen J. Shift work, job stress, and late fetal loss: The National Birth Cohort in Denmark. J Occup environmental Med. 2004 1;46(11):1144-9.

16. Wilson LM, Reid AJ, Midmer DK, Biringer A, Carroll JC, Stewart DE. Antenatal psychosocial risk factors associated with adverse postpartum family outcomes. CMAJ. 1996;154(6):785.

17. Goldstein KM, Martin SL. Intimate partner physical assault before and during pregnancy: how does it relate to women's psychological vulnerability?. Violence and victims. 2004 Aug 1;19(4):387.

Cite this article as: Devisree R, Nirmala C, Indu PS, Remadevi S. Development of antenatal psychosocial stress scale for pregnant women in Kerala. Int J Reprod Contracept Obstet Gynecol 2018;7:1473-9. 